\section{RSP}

http://www.rsp.fsp.usp.br/
Revista de Saúde Pública

\title{
Prevalence of and factors associated with self-reported high blood pressure in Brazilian adults
}

Deborah Carvalho Malta', Regina Tomie Ivata Bernal", Silvânia Suely Caribé de Araújo Andrade'II, Marta Maria Alves da Silva ${ }^{\mathrm{Iv}}$, Gustavo Velasquez-Melendez

I Departamento de Enfermagem Materno Infantil e Saúde Pública. Escola de Enfermagem. Universidade Federal de Minas Gerais. Belo Horizonte, MG, Brasil

" Núcleo de Pesquisas Epidemiológicas em Nutrição e Saúde. Faculdade de Saúde Pública. Universidade de São Paulo. São Paulo, SP, Brasil

III Departamento de Vigilância de Doenças e Agravos Não Transmissíveis e Promoção da Saúde. Secretaria de Vigilância em Saúde. Ministério da Saúde. Brasília, DF, Brasil

ıv Hospital das Clínicas. Universidade Federal de Goiás. Goiânia, GO, Brasil

\section{ABSTRACT}

OBJECTIVE: To analyze factors associated with self-reported high blood pressure among adults in Brazilian state capitals.

METHODS: The study uses data from Sistema de Vigilância de Fatores de Risco e Proteção para Doenças Crônicas por Inquérito Telefônico (Vigitel - Surveillance System of Risk and Protection Factors of Noncommunicable Diseases by Telephone Survey) collected in 2013. Prevalence rates and their respective $95 \%$ confidence intervals by gender were estimated according to sociodemographic variables, lifestyle, reported noncommunicable diseases and self-rated health status. Multivariate logistic regression modeling was used to identify variables associated with self-reported high blood pressure with $\alpha<0.05$.

Correspondence:

Deborah Carvalho Malta

Departamento de Enfermagem Materno Infantil e Saúde Pública, Escola de Enfermagem - UFMG

Av. Alfredo Balena, 190,

Santa Efigênia

30130-100 Belo Horizonte, MG, Brasil

E-mail:dcmalta@uol.com.br

Received: 10 May 2016

Approved: 23 Oct 2016

How to cite: Malta DC, Bernal RTI, Andrade SSCA, Silva MMA, Velasquez-Melendez G. Prevalence of and factors associated with self-reported high blood pressure in Brazilian adults. Rev Saude Publica. 2017;51 Suppl 1:11s

Copyright: This is an open-access article distributed under the terms of the Creative Commons Attribution License, which permits unrestricted use, distribution, and reproduction in any medium, provided that the original author and source are credited.
RESULTS: Prevalence of self-reported high blood pressure among adults living in Brazilian state capitals and the Federal District was $24.1 \%$. The following variables were associated with self-reported high blood pressure: age group, taking 18-24 as reference (all age groups presented increased risk - from 25-34 years [OR $=2.6$; $95 \% \mathrm{CI} 2.0-3.4]$ up to 65 years or more [OR $=28.1$; 95\%CI 21.7-36.4]); low education level (9 to 11 years of study [OR $=0.8 ; 95 \% \mathrm{CI} 0.7-0.9]$ and 12 years or more [OR $=0.6$; $95 \% \mathrm{CI} 0.6-0.7]$ ); Black race or skin color ( $\mathrm{OR}=1.3$; $95 \% \mathrm{CI} 1.1-1.5$ ); being a former smoker ( $\mathrm{OR}=1.2$; 95\%CI 1.1-1.3); obesity ( $\mathrm{OR}=2.7$; 95\%CI 2.4-3.0); diabetes ( $\mathrm{OR}=2.9$; 95\%CI 2.5-3.5\%), and high cholesterol ( $\mathrm{OR}=1.9 ; 95 \% \mathrm{CI} 1.8-2.2)$.

CONCLUSIONS: Approximately one quarter of the adult population living in Brazilian state capitals reported having high blood pressure. Information from Vigitel is useful to monitor high blood pressure and identity its associated factors, supporting public policies for health promotion, surveillance and care.

DESCRIPTORS: Adult. Hypertension, epidemiology. Diagnostic Self Evaluation. Risk Factors. Socioeconomic Factors. Health Surveys. 
a World Health Organization. Global status report on noncommunicable diseases 2010. Geneva: WHO/NUT/ NCD; 2011 [cited 2014 Feb 28]. Available from: http://www. who.int/nmh/publications/ncd_ report2010/en/

${ }^{b}$ World Health Organization. Integrated management of cardiovascular risk: report of a WHO meeting: Geneva; 2002 [cited 2014 Feb 28]. Available from: http://www.who.int/ cardiovascular_diseases/media/ en/635.pdf

${ }^{c}$ Centers for Disease Control and Prevention. National Health and Nutrition Examination Survey.

Atlanta; s.d. [cited 2008 Jan 20]. Available from: http://www.cdc. gov/nchs/about/major/nhanes/ nh3data.htm

${ }^{\mathrm{d}}$ Instituto Brasileiro de Geografia e Estatística. Pesquisa Nacional de Saúde 2013: percepção do estado de saúde, estilos de vida e doenças crônicas - Brasil, grandes regiões e unidades da federação. Brasília (DF): IBGE; 2014 [cited 2015 May 20]. Available from: ftp://ftp.ibge.gov. br/PNS/2013/pns2013.pdf

e Ministério da Saúde (BR), Secretaria de Vigilância em Saúde, Departamento de Vigilância de Doenças e Agravos Não transmissíveis e Promoção da Saúde. VIGITEL Brasil 2013: vigilância de fatores de risco e proteção para doenças crônicas por inquérito telefônico. Brasília, DF: Ministério da Saúde; 2014 [cited 2015 May 20]. Available from: http://portalsaude.saude. gov.br/images/pdf/2014/ dezembro/09/Vigitel-2013.pdf

\section{INTRODUCTION}

Noncommunicable diseases (NCDs) are the main cause of morbidity and mortality, accounting for $63 \%$ of causes of death worldwide. Among them, cardiovascular diseases (high blood pressure, infarction, stroke) stand out for their magnitude, accounting for approximately one third of global death $\mathrm{s}^{\mathrm{a}, \mathrm{b}}$. High blood pressure is the most prevalent circulatory disorder and is often associated with metabolic alterations, which lead to a higher risk for the development of fatal and non-fatal cardiovascular diseases, kidney failure and others ${ }^{1}$.

The World Health Organization (WHO) estimates that about 600 million people are affected by systemic arterial hypertension (SAH) and 7.1 million deaths result from this disease per year. Studies indicate a worldwide growth of $60 \%$ of cases by $2025^{\mathrm{a}}$. High blood pressure leads to an increase in health system costs and has affected the global economy ${ }^{2,3}$.

The risk factors associated with arterial hypertension $\mathrm{AH}$ described in the literature include inadequate eating habits, excessive salt intake, alcohol abuse, physical inactivity, overweight, smoking, and disorders of the glucose and lipid metabolisms ${ }^{1,4,5}$. $\mathrm{AH}$ is a multifactorial clinical condition characterized by high and sustained blood pressure (BP) levels above age-appropriate numbers ${ }^{b}$. There are numerous difficulties in measuring $\mathrm{BP}$ at the population level, and therefore most studies use self-reported information as a proxy for actual $\mathrm{BP}^{6}$. In the United States, a study comparing the self-reported $\mathrm{AH}$ results of the telephone survey Behavioral Risk Factor Surveillance System (BRFSS) with measurement figures from the National Health and Nutrition Examination Survey III show good sensitivity and specificity of self-reported figures ${ }^{\mathrm{c}}$.

In Brazil there are few population-based surveys related to AH prevalence. Most studies have limited comparability due to their local or regional scope and differences in questions and methods. Household surveys in Brazilian municipalities estimate prevalence rates ranging from $15 \%$ to $40 \%$ in the Brazilian urban adult population ${ }^{7.8}$, depending on the methodology and scope of the study. Data from the 2013 National Health Survey (PNS), using self-reported information, estimate a $21.4 \%$ prevalence of high blood pressure for the whole country ${ }^{\mathrm{d}}$.

Population surveys with probability sampling are costly and carried out over large time intervals. The Sistema de Vigilância de Fatores de Risco e Proteção para Doenças Crônicas por Inquérito Telefônico (Vigitel - Surveillance System of Risk and Protection Factors of Noncommunicable Disease by Telephone Survey) has been carried out in the 26 Brazilian state capitals and the Federal District since 2006 and collects information on adult lifestyle and self-reported morbidity, among other topics. It enables annual monitoring of indicators related to NCDs and associated factors to support public policies for health prevention and promotione.

This study aimed to analyze factors associated with high blood pressure in the adult population in the Brazilian state capitals.

\section{METHODS}

The study used Vigitel data collected via telephone survey in 2013 in the adult population (aged $\geq 18$ years) living in the 26 state capitals and the Federal District. This system uses probability samples of the adult population based on the cities' residential landline registries and post-stratification weights calculated by rakinge .

These weights aim to adjust the sociodemographic distributions of the sample to the distribution estimated for the total population of 2013. In calculating the post-stratification weights, the weight of the sample was taken as the inverse of the number of telephone lines and individuals in the household. The post-stratification weight is used to generate all the estimates provided by the system for each one of the cities and for those cities as a whole e $^{\text {. }}$ In 2013, Vigitel interviewed 52,929 adults, about 1,960 in each state capital. 
The Vigitel questionnaire includes approximately 94 questions, divided into modules: demographic and socioeconomic characteristics of individuals, eating and physical activity patterns, reported weight and height, reported morbidity, among otherse .

The outcome analyzed in our study was prevalence of self-reported high blood pressure (HBP), based on a positive response to the question: "Has a doctor ever informed you that you have high blood pressure?"

The explanatory variables were: a) sociodemographic characteristics: gender, age group (18-24, 25-34, 35-44, 45-54, 55-64, 65 or over), schooling ( 0 to 8 years, 9 to 11 years, 12 years or more), race/skin color (white, black, brown), having health insurance (yes, no); b) lifestyle elements as risk factors: smoking (nonsmoker, former smoker, smoker), body mass index classification (normal, overweight, obese), consumption of fatty red meat (yes, no), alcohol abuse (yes, no), high salt intake (yes, no), insufficient physical activity in the domains "leisure," "work," "transport," and "domestic" (yes, no); free time physical activity - at least 150 minutes of moderate-intensity physical activity per week or 75 minutes of moderate physical activity per week - (yes, no); c) protection factor: recommended consumption of fruit and vegetables - five or more portions per day (yes, no); d) self-reported noncommunicable disease: diabetes (yes, no) and high cholesterol (yes, no); e) self-rated health status (good, fair, poor/very poor).

Prevalence rates of high blood pressure and their 95\% confidence intervals (95\%CI) were estimated according to the aforementioned explanatory variables. To test the association between the explanatory variables and prevalence of self-reported high blood pressure, a bivariate analysis was first carried out using a $5 \%$ significance level test of independence. The variables that showed statistically significant association were selected for the multivariate analysis by logistic regression, using the backward method as selection criterion of variables and $5 \%$ significance level for excluding the variable from the model. Data processing and statistical analysis were performed using Stata software version 12.1 (StataCorp., CollegeStation, USA). Odds ratio was used to measure the associations, and sociodemographic variables (race/skin color, health insurance, age, schooling, gender) and metabolic risk factors (diabetes, cholesterol, obesity), eating habits (consumption of fatty red meat, fruit, vegetables, salt intake), alcohol abuse, physical activity and smoking were initially used in model 1 . The variable self-rated health status showed collinearity with other variables and therefore was removed from model 1 . In model 2 , the non-significant variables tested in model 1 were excluded.

The study was approved by the National Human Research Ethics Committee (Opinions $13081 / 2008$ and $355,590 / 2013)$.

\section{RESULTS}

Prevalence of self-reported AH among adults (aged $\geq 18$ years) living in the Brazilian state capitals and the Federal District was $24.1 \%$ (95\%CI 23.4-24.8), being higher in women (26.3\%; 95\%CI 25.4-27.3) and progressing with age, reaching a prevalence rate of $60.4 \%$ (95\%CI 58.362.4) among adults aged 65 and over. Self-reported $\mathrm{AH}$ is higher in individuals with lower schooling levels (38.0\%; 95\%CI 36.5-39.5) and no health insurance (25.3\%; 95\%CI 24.2-26.3). Participants describing themselves as brown-skinned showed the lowest prevalence of selfreported AH (21.4\%; 95\%CI 20.3-22.6) (Table 1).

Regarding lifestyle, prevalence of self-reported AH identified by Vigitel was higher among former smokers (37.4\%; 95\%CI 35.7-39.2), obese individuals (43.9\%; 95\%CI 41.8-45.9), those who do not consume fatty red meat (26.1\%; 95\%CI 25.3-27.0), those who do not consume alcoholic beverages (25.2\%; 95\%CI 24.5-26.0), and adults who self-reported lower salt intake (24.7\%; 95\%CI 23.9-25.5). Among the participants who were insufficiently active in the four domains of physical activity (leisure, work, transport and domestic), prevalence of 
self-reported AH was 29.9\% (95\%CI 28.5-31.2), and was lower among adults who did exercise in their free time, $18 \%$ (95\%CI 17.0-19.0) (Table 2).

Adults who reported diabetes had a prevalence rate of self-reported AH of $67.1 \%$ (95\%CI 64.2-70.0), and among those with high cholesterol, prevalence was 46.3\% (95\%CI 44.5-48.0). Individuals who rated their health status as being poor or very poor had a prevalence rate of self-reported AH of 44.9\% (95\%CI 41.1-48.8) (Table 2).

In the multivariate analysis, model 1 shows the adjustment with all explanatory variables associated with the outcome. The variable "self-rated health status" showed collinearity with other variables in model 1 , and was therefore removed from model 1 . After adjusting for age, gender and schooling, the following variables were not associated with the outcome and were not inserted in model 2: consumption of alcoholic beverages, insufficiency in the four domains of physical activity, recommended consumption of fruit and vegetables ( five or more days per week), consumption of fatty red meat, having health insurance. Skin color was classified as black and others (white and brown) (Table 3).

Model 2 showed the final variables associated with the outcome. Adults most likely to be hypertensive were those who reported as black, obese, with a medical diagnosis of diabetes, and former smokers. There was progressive increase in the likelihood of high blood pressure with age, using the 18 to 24 age group as reference. Increase of schooling levels, on the contrary, was protective of high blood pressure. Male adults showed lower prevalence at the significance limit $(\mathrm{OR}=0.9 ; 95 \% \mathrm{CI} 0.8-1.0 ; \mathrm{p}=0.04)$, and adults who reported high salt intake had a higher probability of high blood pressure, also at the significance limit $(\mathrm{OR}=1.2 ; 95 \% \mathrm{CI} 1.0-1.4)$ (Table 3$)$.

Table 1. Prevalence of self-reported high blood pressure and $95 \% \mathrm{Cl}$ in adults (aged $\geq 18$ years) according to sociodemographic factors for the Brazilian state capitals and Federal District. Vigitel, 2013.

\begin{tabular}{|c|c|c|c|}
\hline Variable & $\%^{\mathrm{a}}$ & $95 \% \mathrm{Cl}$ & $\mathbf{p}^{b}$ \\
\hline Total & 24.09 & $23.39-24.79$ & \\
\hline Gender & & & $<0.001$ \\
\hline Male & 21.5 & $20.4-22.5$ & \\
\hline Female & 26.3 & $25.4-27.3$ & \\
\hline Age group (years) & & & $<0.001$ \\
\hline $18-24$ & 3.0 & $2.4-3.6$ & \\
\hline $25-34$ & 8.1 & $7.1-9.1$ & \\
\hline $35-44$ & 18.3 & $16.8-19.8$ & \\
\hline $45-54$ & 34.1 & $32.2-36.0$ & \\
\hline $55-64$ & 50.3 & $48.1-52.5$ & \\
\hline 65 or over & 60.4 & $58.3-62.4$ & \\
\hline Schooling (years) & & & $<0.001$ \\
\hline $0-8$ & 38.0 & $36.5-39.5$ & \\
\hline $9-11$ & 17.1 & $16.2-17.9$ & \\
\hline 12 or over & 14.6 & $13.6-15.6$ & \\
\hline Race/skin color ${ }^{c}$ & & & $<0.001$ \\
\hline White & 24.1 & $23.0-25.2$ & \\
\hline Black & 25.8 & $23.5-28.1$ & \\
\hline Brown & 21.4 & $20.3-22.6$ & \\
\hline Health insurance & & & $<0.001$ \\
\hline Yes & 22.8 & $21.9-23.7$ & \\
\hline No & 25.3 & $24.2-26.3$ & \\
\hline
\end{tabular}

${ }^{a}$ Weighted percentage to adjust the sociodemographic distribution of the Vigitel sample to the distribution of the adult population of each city projected for 2013

${ }^{\mathrm{b}}$ Test of independence (Chi-square).

${ }^{\mathrm{c}}$ Excluding the skin color categories yellow, red, does not know and did not inform. 
Table 2. Prevalence of self-reported high blood pressure and $95 \% \mathrm{Cl}$ in adults (aged $\geq 18$ years) according to lifestyle, reported noncommunicable diseases and self-rated health status for the Brazilian state capitals and Federal District. Vigitel, 2013.

\begin{tabular}{lcc}
\hline Variable & $\%^{\mathrm{a}}$ & $\mathbf{9 5} \mathbf{c} \mathbf{C l}$ \\
\hline Smoking & & \\
Nonsmoker & 20.1 & $19.3-20.9$ \\
Former smoker & 37.4 & $35.7-39.2$ \\
Smoker & 21.6 & $19.5-23.8$ \\
Body mass index classification & & \\
Normal & 14.9 & $14.1-15.7$ \\
Overweight & 27.3 & $26.0-28.5$ \\
Obesity & 43.9 & $41.8-45.9$
\end{tabular}

Recommended consumption of fruit and vegetables (five or more days per week)

$\begin{array}{lll}\text { Yes } & 25.5 & 24.1-26.9 \\ \text { No } & 23.7 & 22.8-24.5\end{array}$

Consumption of fatty red meat

Yes

No

19.6

26.1

Alcohol abuse

No

Yes

25.2

High salt intake

No

Yes

24.7

20.8

Diabetes

No

Yes

67.1

High cholestero

No

Yes

46.3

Self-rated health status

Good

Average

Poor/very poor

Insufficient physical activity in the four domains ${ }^{c}$

$$
\text { No }
$$

Yes

Physical activity in free time

No

Yes

a Weighted percentage to adjust the sociodemographic distribution of the Vigitel sample to the distribution of the adult population of each city projected for 2013 .

${ }^{b}$ Test of independence (Chi-square).

c Four domains: leisure, work, transport and domestic.
$23.9-25.5$

$19.1-22.6$
$20.2-21.6$

$64.2-70.0$
27.2

18.0
$44.5-48.0$

$$
<0.001
$$

$15.5-17.0$

$35.5-38.4$

$41.1-48.8$

$20.7-22.4$

$28.5-31.2$

$<0.001$

$<0.001$

$<0.001$

$$
\text { 26.3-28.1 }
$$

17.0-19.0
18.4-20.8

$25.3-27.0$

$<0.001$

$$
<0.001
$$

24.5-26.0

16.6-19.9 
Table 3. Multiple association models between selected variables and self-reported high blood pressure in adults (aged $\geq 18$ years) for the Brazilian state capitals and Federal District. Vigitel, 2013.

\begin{tabular}{|c|c|c|c|}
\hline Variable & OR & $95 \% \mathrm{Cl}$ & $\mathbf{p}$ \\
\hline \multicolumn{4}{|l|}{ Model 1} \\
\hline \multicolumn{4}{|c|}{ Race/skin color ${ }^{a}$} \\
\hline White & 1.0 & & \\
\hline Black & 1.3 & $1.1-1.5$ & $<0.01$ \\
\hline Brown & 1.1 & $0.9-1.2$ & 0.10 \\
\hline \multicolumn{4}{|l|}{ Obesity } \\
\hline No & 1.0 & & \\
\hline Yes & 2.7 & $2.4-3.0$ & $<0.01$ \\
\hline \multicolumn{4}{|l|}{ Diabetes } \\
\hline No & 1.0 & & \\
\hline Yes & 2.9 & $2.5-3.5$ & $<0.01$ \\
\hline \multicolumn{4}{|c|}{ High cholesterol } \\
\hline No & 1.0 & & \\
\hline Yes & 1.9 & $1.8-2.2$ & $<0.01$ \\
\hline \multicolumn{4}{|c|}{ Former smoker } \\
\hline No & 1.0 & & \\
\hline Yes & 1.2 & $1.0-1.4$ & 0.01 \\
\hline \multicolumn{4}{|c|}{ High salt intake } \\
\hline No & 1.0 & & \\
\hline Yes & 1.2 & $1.0-1.4$ & 0.02 \\
\hline \multicolumn{4}{|c|}{ Insufficient physical activity in the four domains } \\
\hline No & 1.0 & & \\
\hline Yes & 1.1 & $0.9-1.2$ & 0.07 \\
\hline \multicolumn{4}{|c|}{ Recommended consumption of fruit and vegetables (five or more days per week) } \\
\hline Yes & 1.0 & & \\
\hline No & 1.0 & $0.9-1.1$ & 0.87 \\
\hline \multicolumn{4}{|c|}{$\begin{array}{l}\text { Consumption of fatty } \\
\text { red meat }\end{array}$} \\
\hline Yes & 1.0 & & \\
\hline No & 1.1 & $0.9-1.2$ & 0.26 \\
\hline \multicolumn{4}{|l|}{ Alcohol abuse } \\
\hline No & 1.0 & & \\
\hline Yes & 1.1 & $0.9-1.3$ & 0.26 \\
\hline \multicolumn{4}{|c|}{ Health insurance } \\
\hline Yes & 1.0 & & \\
\hline No & 1.1 & $0.9-1.2$ & 0.12 \\
\hline \multicolumn{4}{|c|}{ Age group (years) } \\
\hline $18-24$ & 1.0 & & \\
\hline $25-34$ & 2.6 & $2.0-3.4$ & $<0.01$ \\
\hline $35-44$ & 5.4 & $4.2-6.9$ & $<0.01$ \\
\hline $45-54$ & 11.1 & $8.6-14.3$ & $<0.01$ \\
\hline $55-64$ & 18.7 & $14.5-24.2$ & $<0.01$ \\
\hline 65 or over & 28.5 & $21.9-37.1$ & $<0.01$ \\
\hline \multicolumn{4}{|c|}{ Schooling (years) } \\
\hline $0-8$ & 1.0 & & \\
\hline $9-11$ & 0.8 & $0.7-0.9$ & $<0.01$ \\
\hline 12 or over & 0.7 & $0.6-0.8$ & $<0.01$ \\
\hline \multicolumn{4}{|l|}{ Gender } \\
\hline Female & 1.0 & & \\
\hline Male & 0.9 & $0.8-0.9$ & 0.02 \\
\hline
\end{tabular}

Continue 
Table 3. Multiple association models between selected variables and self-reported high blood pressure in adults (aged $\geq 18$ years) for the Brazilian state capitals and Federal District. Vigitel, 2013.Continuation

\begin{tabular}{|c|c|c|c|}
\hline Variable & OR & $95 \% \mathrm{Cl}$ & $p$ \\
\hline \multicolumn{4}{|l|}{ Model $2^{b}$} \\
\hline \multicolumn{4}{|l|}{ Race/skin color ${ }^{a}$} \\
\hline White/brown & 1.0 & & \\
\hline Black & 1.3 & $1.1-1.5$ & $<0.01$ \\
\hline \multicolumn{4}{|l|}{ Obesity } \\
\hline No & 1.0 & & \\
\hline Yes & 2.7 & $2.4-3.0$ & $<0.01$ \\
\hline \multicolumn{4}{|l|}{ Diabetes } \\
\hline No & 1.0 & & \\
\hline Yes & 2.9 & $2.5-3.5$ & $<0.01$ \\
\hline \multicolumn{4}{|l|}{ High cholesterol } \\
\hline No & 1.0 & & \\
\hline Yes & 1.9 & $1.8-2.2$ & $<0.01$ \\
\hline \multicolumn{4}{|l|}{ Former smoker } \\
\hline No & 1.0 & & \\
\hline Yes & 1.2 & $1.1-1.3$ & $<0.01$ \\
\hline \multicolumn{4}{|l|}{ High salt intake } \\
\hline No & 1.0 & & \\
\hline Yes & 1.2 & $1.0-1.4$ & 0.02 \\
\hline \multicolumn{4}{|c|}{ Age group (years) } \\
\hline $18-24$ & 1.0 & & \\
\hline $25-34$ & 2.6 & $2.0-3.4$ & $<0.01$ \\
\hline $35-44$ & 5.4 & $4.2-6.9$ & $<0.01$ \\
\hline $45-54$ & 10.9 & $8.6-14.1$ & $<0.01$ \\
\hline $55-64$ & 18.5 & $14.3-23.9$ & $<0.01$ \\
\hline 65 or over & 28.1 & $21.7-36.4$ & $<0.01$ \\
\hline \multicolumn{4}{|l|}{ Schooling (years) } \\
\hline $0-8$ & 1.0 & & \\
\hline $9-11$ & 0.8 & $0.7-0.9$ & $<0.01$ \\
\hline 12 or over & 0.6 & $0.6-0.7$ & $<0.01$ \\
\hline \multicolumn{4}{|l|}{ Gender } \\
\hline Female & 1.0 & & \\
\hline Male & 0.9 & $0.8-1.0$ & 0.04 \\
\hline
\end{tabular}

Notes: Weighted percentage to adjust the sociodemographic distribution of the Vigitel sample to the distribution of the adult population of each city projected for 2013.

axcluding the skin color categories yellow, red, does not know and did not inform.

${ }^{\mathrm{b}}$ Non-significant variables in Model 1 were excluded.

\section{DISCUSSION}

The findings of this study show that about a quarter of the adult population living in the Brazilian state capitals reports having $\mathrm{AH}$. The variables associated with $\mathrm{AH}$ were: increasing age and aging, low schooling levels, black race/skin color, obesity, self-reported diabetes or high cholesterol, being a former smoker, and high salt intake. The variable female gender was at significance limit.

Prevalence of AH observed in the 2013 Vigitel was similar to that described in Brazil and worldwide using self-reported diagnosis ${ }^{7,9, d}$. Among the multiple elements that contribute to determine $\mathrm{AH}$ are genetic factors (age, gender, family history), lifestyle (smoking, obesity, alcohol abuse, physical inactivity, stress and high salt intake), physical and psychosocial setting (stress, schooling), the organization of health services and the relationships between these various elements, some of which are shown in this study ${ }^{9,10}$. 
${ }^{\mathrm{f}}$ World Health Organization.

World health statistics 2012.

Geneva: WHO; 2012 [cited 2013

Feb 14]. Available from: http:// www.who.int/gho/publications/ world_health_statistics/2012/en/

${ }^{\mathrm{g}}$ Instituto Brasileiro de Geografia e Estatística. Pesquisa Nacional por Amostra de Domicílios: um panorama da saúde no Brasil: acesso e utilização de serviços, condições de saúde e fatores de risco e proteção à saúde 2008. Rio de Janeiro: IBGE; 2010 [cited 2013 Feb 14]. Available from: http://www.ibge.gov.br/home/ estatistica/populacao/panorama_ saude_brasil_2003_2008/ PNAD_2008_saude.pdf
In this study, women showed higher prevalence of self-reported AH, but at the significance limit after adjustment for several covariates. WHO data show that prevalence of AH among men is higher than among women, both worldwide (29.2\% for men and $24.8 \%$ for women) and in the Americas (26.3\% for men and $19.7 \%$ for women) $)^{f}$. Considering the findings of studies with selfreported data, women showed higher prevalence of $\mathrm{AH}^{4,7,11}$. The greater demand for health services by women may represent a greater opportunity for the medical diagnosis of $\mathrm{AH}^{4,12}$. Therefore, such higher prevalence does not necessarily indicate a higher risk of high blood pressure among women.

The relationship between $\mathrm{AH}$ prevalence and increasing age has been widely reported ${ }^{10, \mathrm{a}}$. In the age group over 65 , prevalence of $\mathrm{AH}$ was above $60 \%$ and may be explained by aging-specific biological alterations, such as arterial stiffening and increased peripheral vascular resistance ${ }^{10,13}$.

Prevalence of AH was higher among black race/skin color adults, followed by whites and browns. Among men, there was no difference according to race/skin color. Studies show higher prevalence of AH among blacks ${ }^{14,15}$. In Brazil, Lessa ${ }^{9}$ found prevalence rates up to $130 \%$ higher among black women compared to white women. In the literature, the probable factors related to higher prevalence of AH in the black population are genetic predisposition, worse living conditions, less access to health services and stress due to racial discrimination ${ }^{9, g}$.

No differences were found in this study related to having or not health insurance. Having health insurance may facilitate access to health services and preventive action ${ }^{13}$. However, the higher schooling levels among respondents with health insurance may be responsible for the loss of statistical significance in the multivariate model.

The literature evidences smoking as a strong risk factor for cardiovascular diseases ${ }^{16, a}$, and smoking cessation is recommended as a priority measure in the secondary prevention of cardiovascular diseases and other NCDs ${ }^{16, a}$. This study showed the association between smoking (former smoker) and AH. This association may be due to an effect resulting from the crosssectional study design: former smokers may have abandoned the addiction following medical advice after the diagnosis of high blood pressure, given the harmful effects of smoking. Another explanation may be that smoking cessation triggers weight gain, increasing the risk of AH. Indeed, the association between former smokers and diabetes has already been observed in longitudinal studies, probably due to weight gain after smoking cessation caused by metabolic factors ${ }^{17}$, but the relationship between former smokers and AH still needs to be investigated in further studies.

Obesity is an important risk factor for high blood pressure ${ }^{\mathrm{a}, \mathrm{b}}$. This study found a positive gradient between overweight/obesity and AH prevalence. Obese people would be up to three times more likely to develop $\mathrm{AH}^{18}$. Thus, losing weight is the most effective method for reducing blood pressure in obese individuals, as well as contributing to the reduction of antihypertensive dosages ${ }^{10}$.

The consumption of five or more daily portions of fruit and vegetables is recommended by the WHO to reduce the incidence of $\mathrm{NCDs}^{\mathrm{a}, \mathrm{b}}$ and prevent and treat overweight and diabetes ${ }^{10,19, a}$. This study did not find a direct association between the recommended consumption of fruit and vegetables and $\mathrm{AH}$. A higher prevalence of $\mathrm{AH}$ was observed among adults who reported consuming fatty red meat. However, consumption of fatty red meat was not included in the final model. Consumption of fatty meat is recognized as a risk factor for cardiovascular diseases ${ }^{\mathrm{a}}$.

Alcohol intake causes changes in blood pressure and is associated with increased cardiovascular morbidity and mortality ${ }^{20}$, although this association was not found in the current study.

High salt intake was associated with higher prevalence of AH at the significance limit. High salt intake is harmful to the health and is associated with AH. This relationship is partly caused by increased water retention in the body, overloading the cardiac function and potentially resulting in high blood pressure ${ }^{21, a}$.

Diabetes and high cholesterol also showed an association with AH among adults interviewed in the 2013 Vigitel. The association between diabetes and AH is established by pathophysiological mechanisms, and prevention and treatment of these comorbidities (AH, diabetes and high 
cholesterol) are essential in controlling more severe outcomes and preventing mortality ${ }^{19}$. Eating fatty foods increases blood cholesterol levels and also poses a higher risk of heart disease.

AH prevalence among individuals who self-rated their health as poor or very poor was almost twice as high. This may be associated with both the symptoms and the changes brought about by the disease, such as a greater number of medical appointments and visits to health services, changes in lifestyle, use of medicines and restriction of daily activities, leading to the perception of worsening health conditions ${ }^{22}$. However, the poor self-evaluation was not included in the final model, presenting collinearity with other variables.

In this study, participants who were insufficiently active in the four domains (leisure, work, transport and domestic) showed higher prevalence of $\mathrm{AH}$, as did those who were not active in their leisure time. The importance of physical activity for the treatment and reduction of AH prevalence and, consequently, of mortality caused by cardiovascular diseases is recognized ${ }^{19}$; however, the variables related to physical activity were not included in the final model.

One limitation of this study is the fact that the cross-sectional design measures the event and outcomes simultaneously. As a behavior change may occur due to the event being studied, the associations herein described must be viewed with caution regarding the causal model. Another limitation is the possibility that $\mathrm{AH}$ prevalence is underestimated, since high blood pressure may be subclinical or undiagnosed in a large part of the population studied.

The Vigitel telephone survey has limitations, such as restricting the sample to individuals residing in Brazilian state capitals and the Federal District who have a landline phone. This is minimized by the use of data weighting factors, which seek to adjust the demographic characteristics of the Vigitel sample to the characteristics of the total population, according to population census data ${ }^{\mathrm{e}}$.

Aging, black race/skin color, low schooling levels, obesity, being a former smoker, reporting diabetes and high cholesterol, in addition to high salt intake, were associated with a higher risk of AH among adults living in the 26 Brazilian capitals and the Federal District in 2013. Information from Vigitel is useful to monitor the historical series of AH prevalence and identity its associated factors, and this study may help support public policies for health promotion, surveillance and care in the Brazilian Unified Health System ${ }^{23}$.

\section{REFERENCES}

1. Ribeiro AB, Plavnik. Atualização em hipertensão arterial: clínica, diagnóstico e terapêutica. 2.ed. São Paulo: Atheneu; 2007.

2. Balu S, Thomas J 3rd. Incremental expenditure of treating hypertension in the United States. Am J Hypertens. 2006;19(8):810-6. https://doi.org/10.1016/j.amjhyper.2005.12.013.

3. Kearney PM, Whelton M, Reynolds K, Muntner P, Whelton PK, He J. Global burden of hypertension: analysis of worldwide data. Lancet. 2005;365(9455):217-23. https://doi.org/10.1016/S0140-6736(05)17741-1.

4. Ferreira SRG, Moura EC, Malta DC, Sarno F. Frequência de hipertensão arterial e fatores associados: Brasil, 2006. Rev Saude Publica. 2009;43 Supl 2:98-106. https://doi.org/10.1590/S0034-89102009000900013.

5. Lino MZR, Muniz PT, Siqueira KS. Prevalência e fatores associados ao excesso de peso em adultos: inquérito populacional em Rio Branco, Acre, Brasil, 2007-2008. Cad Saude Publica. 2011;27(4):797-810. https://doi.org/10.1590/S0102-311X2011000400019.

6. Lima-Costa MF, Peixoto SV, Firmo JOA. Validade da hipertensão arterial auto-referida e seus determinantes (projeto Bambuí). Rev Saude Publica. 2004;38(5):637-42. https://doi.org/10.1590/S0034-89102004000500004.

7. Andrade SSCA, Malta DC, Iser BM, Sampaio PC, Moura LD. Prevalence of self-reported arterial hypertension in Brazilian capitals in 2011 and analysis of its trends in the period between 2006 and 2011. Rev Bras Epidemiol. 2014;17 Supl 1:215-26. https://doi.org/10.1590/1809-4503201400050017. 
8. Lessa, I. Hipertensão arterial sistêmica no Brasil: tendência temporal [editorial]. Cad Saude Publica. 2010;26(8):1470. https://doi.org/10.1590/S0102-311X2010000800001.

9. Lessa I. Epidemiologia da hipertensão arterial sistêmica e insuficiência cardíaca no Brasil. Rev Bras Hipertens. 2001;8(4):383-92.

10. Sociedades Brasileiras de Hipertensão; Sociedade Brasileira de Cardiologia; Sociedade Brasileira de Nefrologia. Diretrizes Brasileiras de Hipertensão Arterial. Rio de Janeiro: Sociedade Brasileira de Cardiologia; 2010.

11. Malta DC, Iser BPM, Claro RM, Moura L, Bernal RTI, Nascimento AF, et al. Prevalência de fatores de risco e proteção para doenças crônicas não transmissíveis em adultos: estudo transversal, Brasil, 2011. Epidemiol Serv Saude. 2013;22(3):423-34. https://doi.org/10.5123/S1679-49742013000300007.

12. Pereira M, Lunet N, Azevedo A, Barros H. Differences in prevalence, awareness, treatment and control of hypertension between developing and developed countries. J Hypertension. 2009;27(5):963-75. https://doi.org/10.1097/HJH.0b013e3283282f65.

13. Cesarino CB, Cipullo JP, Martin JFV, Ciorlia LA, Godoy MRP, Cordeiro JA, et al. Prevalência e fatores sociodemográficos em hipertensos de São José do Rio Preto. Arq Bras Cardiol. 2008;91(1):31-5. https://doi.org/10.1590/S0066-782X2008001300005.

14. Gravlee CC, Dressler WW, Bernard HR. Skin color, social classification, and blood pressure in Southeastern Puerto Rico. Am J Public Health. 2005;95(12):2191-7. https://doi.org/10.2105/AJPH.2005.065615.

15. Klonoff EA, Landrine $\mathrm{H}$. Is skin color a marker for racial discrimination? Explaining the skin color-hypertension relationship. J Behav Med. 2000;23(4):329-38. https://doi.org/10.1023/A:1005580300128.

16. National Institutes of Health State-of-The Science conference statement: tobacco use: prevention, cessation, and control. Ann Intern Med. 2006;145(11):839-44. https://doi.org/10.7326/0003-4819-145-11-200612050-00141.

17. Yeh HC, Duncan BB, Schmidt MI, Wang NY, Brancati FL. Smoking, smoking cessation, and risk for type 2 diabetes mellitus: a cohort study. Ann Intern Med. 2010;152(1):10-7. https://doi.org/10.7326/0003-4819-152-1-201001050-00005.

18. Galvão R, Kohlmann Jr O. Hipertensão arterial no paciente obeso. Rev Bras Hipertens. 2002;9(3):262-7.

19. Sociedade Brasileira de Diabetes. Diretrizes SBD. Rio de Janeiro: SBD; 2011.

20. Sesso HD, Cook NR, Buring JE, Manson JE, Gaziano JM. Alcohol consumption and the risk of hypertension in women and men. Hypertension. 2008;51(4):1080-7. https://doi.org/10.1161/HYPERTENSIONAHA.107.104968.

21. Whelton PK1, Appel LJ, Espeland MA, Applegate WB, Ettinger WH Jr, Kostis JB, et al. Sodium reduction and weight loss in the treatment of hypertension in older persons: a randomized controlled trial of non-pharmacologic interventions in the elderly (TONE). JAMA. 1998;279(11):839-46. https://doi.org/10.1001/jama.279.11.839.

22. Barros MBA, Zanchetta LM, Moura EC, Malta DC. Auto-avaliação de saúde e fatores associados, Brasil, 2006. Rev Saude Publica. 2009;43 Suppl 2:27-37. https://doi.org/10.1590/S0034-89102009000900005.

23. Malta DC, Dimech CPN, Moura L, Silva Jr JB. Balanço do primeiro ano da implantação do Plano de Ações Estratégicas para o Enfrentamento das Doenças Crônicas Não Transmissíveis no Brasil, 2011 a 2022. Epidemiol Serv Saude. 2013;22(1):171-8. https://doi.org/10.5123/S1679-49742013000100018.

Funding: Conselho Nacional de Desenvolvimento Científico e Tecnológico (CNPq - Processo 307865/2014-2 productivity grant to DMC) and Convênio Fundo Nacional de Saúde and Universidade Federal de Minas Gerais (FNS/UFMG - Processo 86).

Authors' Contribution: Study design, first draft of manuscript, literature review, data analysis and interpretation and critical revision: DCM. Statistical analysis, data analysis and interpretation, critical revision of text: RTIB. Literature review, data analysis and interpretation, critical revision of text: SSCA, GVM. Data analysis, critical revision of manuscript: MMAS. All authors approved the final version and take public responsibility for the article's content.

Conflict of Interest: The authors declare no conflict of interest. 